Available online at www.banglajol.info

Bangladesh J. Sci. Ind. Res. 51(1), 61-68, 2016
BANGLADESH JOURNAL OF SCIENTIFIC AND INDUSTRIAL RESEARCH

E-mail: bjsir07@gmail.com

\title{
Assessment of yield stability of maize inbred lines in multi-environment trials
}

\author{
M. A. Miah ${ }^{1 *}$, S. Ahmed ${ }^{2}$ and M. S. Uddin ${ }^{3}$ \\ ${ }^{1}$ Plant Breeding Division, Regional Agricultural Research Station, Jessore, Bangladesh \\ ${ }^{2}$ Plant Breeding Division, Bangladesh Agricultural Research Institute, Gazipur, Bangladesh \\ ${ }^{3}$ Plant Breeding Division, Regional Agricultural Research Station, Barisal, Bangladesh
}

\begin{abstract}
Stable performance of maize hybrids at a specific growing region is critical for obtaining high and stable yield. The objectives of this study were to assess grain yield stability of fourteen maize inbred lines from five different diverse regions of Bangladesh during 2010 - 2011 growing season (rabi) using genotype main effect plus genotype by environment interaction (GGE) biplot and to identify maize inbred lines that have both high mean yield and stable yield performance across test environments of Bangladesh. The GGE biplot method was effective in recognition that the inbreds G2 and G13 to be the most desirable ones for growing in Jessore (E1), G6 and G8 in Gazipur (E2), G3 in Rahmatpur (E3) and G1, G12, G14 and G9 in Debiganj (E5) region. The inbreds G5 and G7 had average grain yield and high stability, whereas the inbred line G10 had high grain yield and high stability. Besides, the inbred line G13 was the least stable across different environments. This technique can serve as a useful tool for recommendation of maize inbreds for specific growing regions taking into account the specificities of hybrids and growing conditions.
\end{abstract}

Keywords: Maize; GGE biplot; Stability; Genotype $\times$ environment interaction

\section{Introduction}

Maize is the third most important cereal crop in the world, after wheat and rice, in terms of cultivated area, production and grain yield (FAO, 2015). The production of maize in Bangladesh is 1.49 million ton with an average grain yield of $6.62 \mathrm{t} \mathrm{ha}^{-1}$ (FAO, 2015). It is a versatile crop that adapts easily to a wide range of production environments (Gerpacio and Pingali, 2007).

An important objective of maize breeding programs is to develop new inbred lines that combine well to produce higher grain yields and superior agronomic performance in hybrid combinations. The most important breeding method for development of inbred lines is selection within either second filial (F2) or backcross populations widely known as pedigree selection (Hallauer, 1990). In such breeding programs, the choice of parents is crucial (Hallauer and Miranda, 1988). This decision will find out the genetic constitution of the source population, which in turn resolves the likelihood of picking a new superior line.

Very little information is available on how to select parents to cross in pedigree breeding programs and breeders rely primarily on pedigree and performance data (Lamkey and Lee, 1993). To select parents supplementary information about the lines, their performance in hybrid combinations, stability in crosses over environments, drawbacks, strengths and direct comparisons with allied lines would be incredibly useful.

The most important breeding objective is to get better yield. Other main agronomic traits however are of importance in hybrid combinations and hold an impact on yield. Information on the performance of inbred lines per se can be accumulated in breeding nurseries, and this information is helpful for making choice for future parents in a pedigree breeding program. However, for information of how lines behave in crosses, their performance in crosses must be estimated (Hallauer and Miranda, 1988) and this information is used to go for parents for novel source populations.

Grain yield stability is influenced by the capacity of a genotype to react to environmental conditions, which is determined by the genotype's genetic structure (Shiri, 2013). Genotype $\times$ environment $(\mathrm{G} \times \mathrm{E})$ interaction alters the relative grain yield of genotypes in different environments and makes it difficult to select superior genotypes (Gauch, 2006; Cornelius and Crossa, 1999). Generally, different genotypes behave differently because of differences in gene responses or in their potential performance in different environments (Brandiej and Meverty, 1994). $\mathrm{G} \times \mathrm{E}$ interaction decreases the association between genotype and phenotype, which in turn diminishes the progress of genotype selection. Stability

*Corresponding author. e-mail: alamgir_magura@yahoo.com 
analysis is the most important method used to discover the nature of $\mathrm{G} \times \mathrm{E}$ interaction by which stable and consistent genotypes can be identified and selected (Cornelius and Crossa, 1999; Perkins and Jinks, 1971).

Different approaches have been suggested for evaluating $G$ $\times$ E interaction and identifying stable genotypes (Becker and Leon, 1988; Karimizadeh et al., 2006). Although utilizing non-parametric and single-variable parametric methods is easy, they do not perfectly interpret the multi-dimensional and complicated nature of $\mathrm{G} \times \mathrm{E}$ interaction. Therefore, multivariate analysis methods have been proposed to solve the problem (Moreno-Gonzalez et al., 2004). Among multivariate analysis methods, biplot methods are based on principal component analysis (Yan et al., 2000; Kempton, 1984; Gauch and Zobel, 1997; Gabriel, 1971). Different versions of biplot methods based on multivariate statistics have been introduced and widely used in agricultural research by plant breeders for graphical analysis of $\mathrm{G} \times \mathrm{E}$ interaction (Yan and Tinker, 2006; Gauch, 2006; Yan et al., 2000).

GGE biplot is a particular version of a biplot that offers information on genotype main effects and $\mathrm{G} \times \mathrm{E}$ interaction at the same time. In contrast to typical multivariate stability analysis methods where only $\mathrm{G} \times \mathrm{E}$ interaction is considered, this method also includes genotype main effects. Studies have shown that in most stability analysis experiments, the main effect of environment is high, while variations determined by the main effect of genotype and $\mathrm{G} \times \mathrm{E}$ interaction that are logical and understandable are low. Genotypic and $G$ $\times E$ interaction sources of variation are used in the GGE biplot method to achieve more dependable results as the location is not a convenient factor.

The GGE biplot method aids plant breeders to simply assess genotypic stability and combinations of genotypic stability and yield in diverse environments since it graphically displays $\mathrm{G} \times \mathrm{E}$ interaction effects. It also permits assessing the correlation among environments and helps the rearrangement of target environments in plant breeding programs. This method has been applied for stability analysis to assess genotypes in multi-environment trials of maize (Fan et al., 2007; Shiri et al., 2010 and Choukan, 2011), wheat (Yan et al., 2001 and Yan and Hunt, 2002), durum wheat (Mohammadi et al., 2010), soybean (Yan and Rajcan, 2002), barley (Dehghani et al., 2006) and cotton (Blanche and Myers, 2006 and Dimitrios et al., 2008).

Deciding and clustering of target environments in plant breeding programs are one of the key applications of the GGE biplot method. The environments being assessed are grouped into different clusters with the same genotype reaction. Environment grouping using GGE biplot analysis has been reported for different crops such as wheat (Yan and Tinker, 2006; Kaya et al., 2006 and Bavandpori et al., 2015), durum wheat (Mohammadi et al., 2010; 2012 and Letta et al., 2008), barley (Mohammadi et al., 2009), soybean (Yan and Rajcan, 2002), rice (Samonte et al., 2005) and maize (Meseka et al., 2008 and Choukan, 2011).

The purpose of this investigation was: (1) to evaluate the grain yield stability of 14 maize inbred lines tested across five locations applying GGE biplot model and (2) to identify maize inbred lines that have both high mean yield and stable yield performance across test environments of Bangladesh.

\section{Materials and methods}

This research was carried out at five locations (environments) i.e. the Regional Agricultural Research Station, Jessore; Bangladesh Agricultural Research Institute, Joydebpur; Regional Agricultural Research Station,

Table I. Environments utilized in the evaluation of the inbred lines of maize in the growing season (November, 2010April, 2011) Bangladesh

\begin{tabular}{|c|c|c|c|c|c|c|c|c|}
\hline $\begin{array}{c}\text { Environ- } \\
\text { ment }\end{array}$ & Code & Upazila & $\begin{array}{l}\text { Latitude } \\
\left({ }^{\circ} \mathrm{N}\right)\end{array}$ & $\begin{array}{c}\text { Longitude } \\
\left({ }^{\circ} \mathrm{E}\right)\end{array}$ & Altitude & $\begin{array}{l}\text { Max.temp. } \\
\left({ }^{\circ} \mathrm{C}\right)\end{array}$ & $\begin{array}{c}\text { Min.temp. } \\
\left({ }^{\circ} \mathrm{C}\right)\end{array}$ & $\begin{array}{c}\text { Rainfall } \\
(\mathrm{mm})\end{array}$ \\
\hline 1 & E1 & $\begin{array}{l}\text { Jessore } \\
\text { sadar, JE }\end{array}$ & 23.18 & 89.19 & $11 \mathrm{~m}$ & $\begin{array}{l}42.0 \\
0\end{array}$ & 6.80 & 39.30 \\
\hline 2 & E2 & $\begin{array}{l}\text { Joydebpur, } \\
\text { GA }\end{array}$ & 23.99 & 90.41 & $13 \mathrm{~m}$ & $\begin{array}{l}35.3 \\
7\end{array}$ & 9.35 & 124.00 \\
\hline 3 & E3 & $\begin{array}{l}\text { Rahmatpur, } \\
\text { BA }\end{array}$ & 22.70 & 90.30 & $5 \mathrm{~m}$ & $\begin{array}{l}36.3 \\
3\end{array}$ & 11.61 & 183.00 \\
\hline 4 & E4 & $\begin{array}{l}\text { Hathazari, } \\
\text { CH }\end{array}$ & 22.53 & 91.80 & $5 \mathrm{~m}$ & $\begin{array}{l}32.0 \\
0\end{array}$ & 10.50 & 183.00 \\
\hline 5 & E5 & $\begin{array}{l}\text { Debiganj, } \\
\text { PA }\end{array}$ & 26.12 & 88.75 & $62 \mathrm{~m}$ & $\begin{array}{l}31.7 \\
4\end{array}$ & 12.89 & 56.87 \\
\hline
\end{tabular}


Rahmatpur; Regional Agricultural Research Station, Hathazari and Breeders' Seed Production Centre, Debiganj (Table I) which correspond to the South-West, Central, South, South-East and North-West areas of Bangladesh distributed in the districts of Jessore (JE), Gazipur (GA), Barisal (BA), Chitagong $(\mathrm{CH})$ and Panchagarh (PA) respectively. These five locations were represented as E1, E2, E3, E4 and E5, respectively.

Fourteen quality protein maize (QPM) inbred lines were used in this trial (Table II). The experiment was conducted during November 2010 to April, 2011 following Alpha Lattice design with two replications and six blocks. The plots were made up of single 5-m row, using a population density of 66,666 plants per hectare. Fertilizers were applied at the rate of 120:35:70:40:5:1 kg/ha of N, P, K, S, Zn and B, respectively. Grain yield $\left(\mathrm{t} \mathrm{ha}^{-1}\right)$ for each inbred was adjusted to $15.5 \%$ grain moisture content.

Table II. TMaize inbred lines included in the study

\begin{tabular}{lllc}
\hline $\begin{array}{l}\text { Inbred } \\
\text { code }\end{array}$ & \multicolumn{1}{c}{ Name } & \multicolumn{1}{c}{ Pedigree } & Source \\
\hline G1 & CL02450Q & CL02450Q & CIMMYT, Mexico \\
G2 & CLQG2508 & CLQG2508 &, \\
G3 & CLQRCYQ40 & CLQRCYQ40 &, \\
G4 & CLQRCYQ44 & CLQRCYQ44 &, \\
G5 & CLQ-RCYQ49 & CLQ-RCYQ49 &, \\
G6 & CLQRCYQ59 & CLQRCYQ59 &, \\
G7 & CLQRCYQ60 & CLQRCYQ60 &, \\
G8 & CLQ-RCYQ62 & CLQ-RCYQ62 &, \\
G9 & CLQRCYQ67 & CLQRCYQ67 &, \\
G10 & CLQ-S89YQ04 & CLQ-S89YQ04 &, \\
G11 & CLQS89YQ06 & CLQS89Y06 &, \\
G12 & CML451Q & CML451Q &, \\
G13 & CML161 & CML161 &, \\
G14 & CML165 & CML165 &, \\
\hline
\end{tabular}

Genotype and genotype $\times$ environment (GGE) biplot analyses were performed using Plant Breeding Tools (PBTools) software version 1.4 (PBTools, 2014). GGE biplot analysis was also used to generate graphs for: (i) comparing environments to the ideal environment which is the one that is most discriminating for genotypes, (ii) the "What-won-where" pattern where specific genotypes can be recommended to specific environments and (iii) environment vector which is the distance between the marker of the environment to the plot origin.

The angles between environment vectors were used to judge correlations (similarities/dissimilarities) between pairs of environments (Yan and Kang, 2003).

\section{Results and discussion}

The combined analysis of variance for grain yield displayed highly significant effects of environment, genotypes and $G \times$ $\mathrm{E}$ interaction (Table III). Results indicated variation in the grain yield performance of the inbred lines in different environments and suggested that it would be more appropriate to select superior maize inbreds based on a combination of good yield stability and high grain yield than on grain yield only. A large proportion (54.14\%) of the total variation in grain yield was produced by the location effect. Substantial sum of squares for environment indicated that the environments were dissimilar, and that big differences among environmental means brought about most of the variation in grain yield.

$\mathrm{G} \times \mathrm{E}$ interaction accounted for $36.77 \%$ of the total variation in grain yield, while genotype accounted for only $5.59 \%$ (Table III). The $\mathrm{G} \times \mathrm{E}$ interaction sum of squares was 6.6 times larger than that for genotypes, indicating that there were substantial differences in inbred responses across environments.

Table III. Combined analysis of variance for grain yield of maize inbred lines

\begin{tabular}{lllll}
\hline SV & df & SS & MS & \% of total \\
\hline Environment & 4 & 167.89 & $41.97^{* *}$ & 54.14 \\
Error 1 & 5 & 0.06 & 0.01 & 0.02 \\
Genotypes & 13 & 17.34 & $1.33^{* *}$ & 5.59 \\
G $\times$ E & 52 & 114.03 & $2.19^{* *}$ & 36.77 \\
Error 2 & 65 & 10.76 & 0.17 & 3.47 \\
\hline
\end{tabular}

While $\mathrm{G} \times \mathrm{E}$ interaction was highly significant, the combined analysis of variance (ANOVA) could not justify the grain yield stability of inbred lines. Therefore, $\mathrm{G} \times \mathrm{E}$ interaction effects should be estimated using appropriate statistical methods to identify stable inbreds. The graphical GGE biplot method was utilized to explore environmental variation and interpret $\mathrm{G} \times \mathrm{E}$ interaction. 
To draw the biplot, data obtained from the multivariate models of inbreds and environments should be used simultaneously in one figure. This GGE biplot is shown to identify effectively the GEI pattern of the data. A GGE biplot is constructed by plotting the first two principal components (PC1 and PC2, also referred to as primary and secondary effects, respectively) derived from singular value decomposition (SVD) of the environment-centered data (Yan et al., 2001; Mohammadi et al., 2010).

GGE biplot analysis was performed on the 5-locations (as environments) grain yield data of maize inbred lines. Results proved that the GGE biplot explained $73.80 \%$ of genotype main effects and the $\mathrm{G} \times \mathrm{E}$ interaction. The PC1 and PC2 explained $54.0 \%$ and $19.8 \%$ of genotype main effects and $\mathrm{G}$ $\times$ E interaction, respectively (Fig. 1).
The GGE biplot was used to represent the polygon for $\mathrm{G} \times \mathrm{E}$ interaction effect from which distinctive interpretations can be obtained as well. The polygon is formed by connecting the markers of the genotypes that are far away from the biplot origin such that all other genotypes are contained in the polygon. The polygon view of a biplot is the best way to visualize the interaction patterns between genotypes and environments, and to effectively interpret a biplot. It clearly shows which genotype won in which environments, thus facilitating megaenvironment identification (Yan et al., 2000 and Dimitrios et al., 2008).

The polygon of the fourteen maize inbred lines under five locations is shown in Fig. 1. Different researchers have used

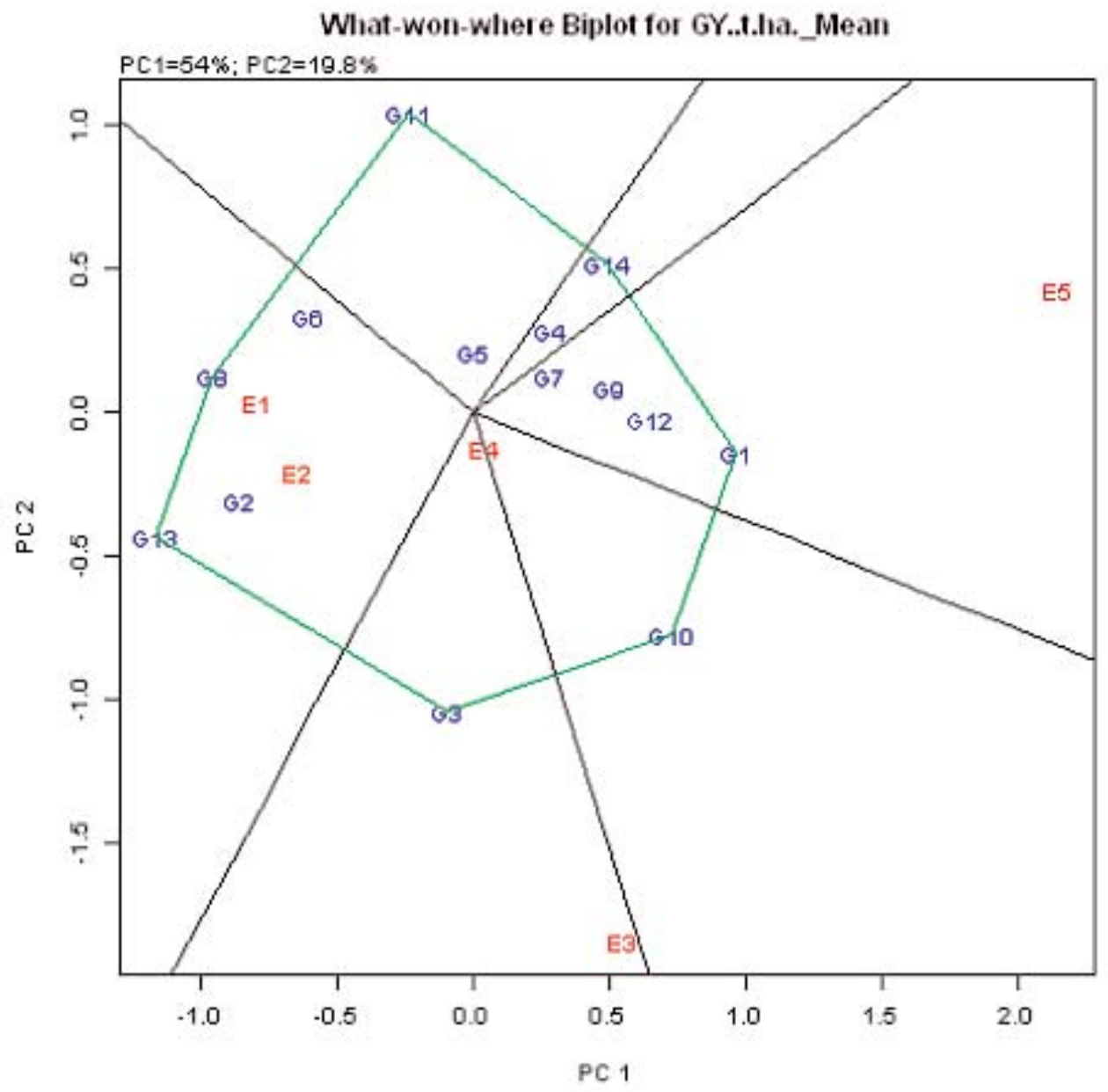

Fig. 1. Polygon of GGE biplot method for grouping environments. Environments are denoted by 'E' while inbreds are marked with ' $G$ ' 
this method as well (Choukan, 2011; Sabaghnia et al., 2008 and Yan et al., 2000). Inbreds G1, G10, G3, G13, G8, G11 and G14 are located at the top of the polygon. These inbreds are the strongest or weakest ones in some or all environments in terms of grain yield, since they are located at the maximum distance from the biplot origin (Fig. 1). Although the inbred G11 was located at the top of the polygon, it produced low grain yield in all test environments.

The two environments (E1 and E2) were positioned in the same sector on the graph, which suggests that those environments did not vary significantly between themselves. The inbred G6 was the highest yielding in Jessore (E1) followed by G13, G4 and G14. But G4 and G14 fell in different sector in the graph. So, only G6 and G13 may perform better than others in E1. Similarly, the inbred G8 exhibited the highest yield in Joydebpur (E2) and obviously fell in the same sector with E2. The environment Rahmatpur (E3) was placed in a different sector with only one inbred G3 showing the highest grain yield. The location Hathazari (E4) was positioned over a divider line of two sectors and near the origin of the biplot which made it difficult for prediction of performance of inbreds in this location. The inbred lines G1 and G12 showed the highest grain yield followed by G9 and G7 and fell in the same sector with Debiganj (E5). So, these genotypes may perform better in E5. None of the environments fell in the sectors with genotypes G5, G4, G14 and G11, indicating that these genotypes are not suitable for growing at these specific locations.

Grain yield performance and stability were evaluated using an average environment coordination (AEC) method (Yan et al., 2001; Yan and Hunt, 2002). In this technique, an average environment, symbolized by a small circle, is defined by the average PC1 and PC2 scores of all environments. A line is then drawn that goes by this average environment and the biplot origin; this line is called the average environment axis and specifies to higher average grain yield. The line that goes by the origin and is perpendicular to the AEC (average environment coordinate) with arrows on bothends stands for the

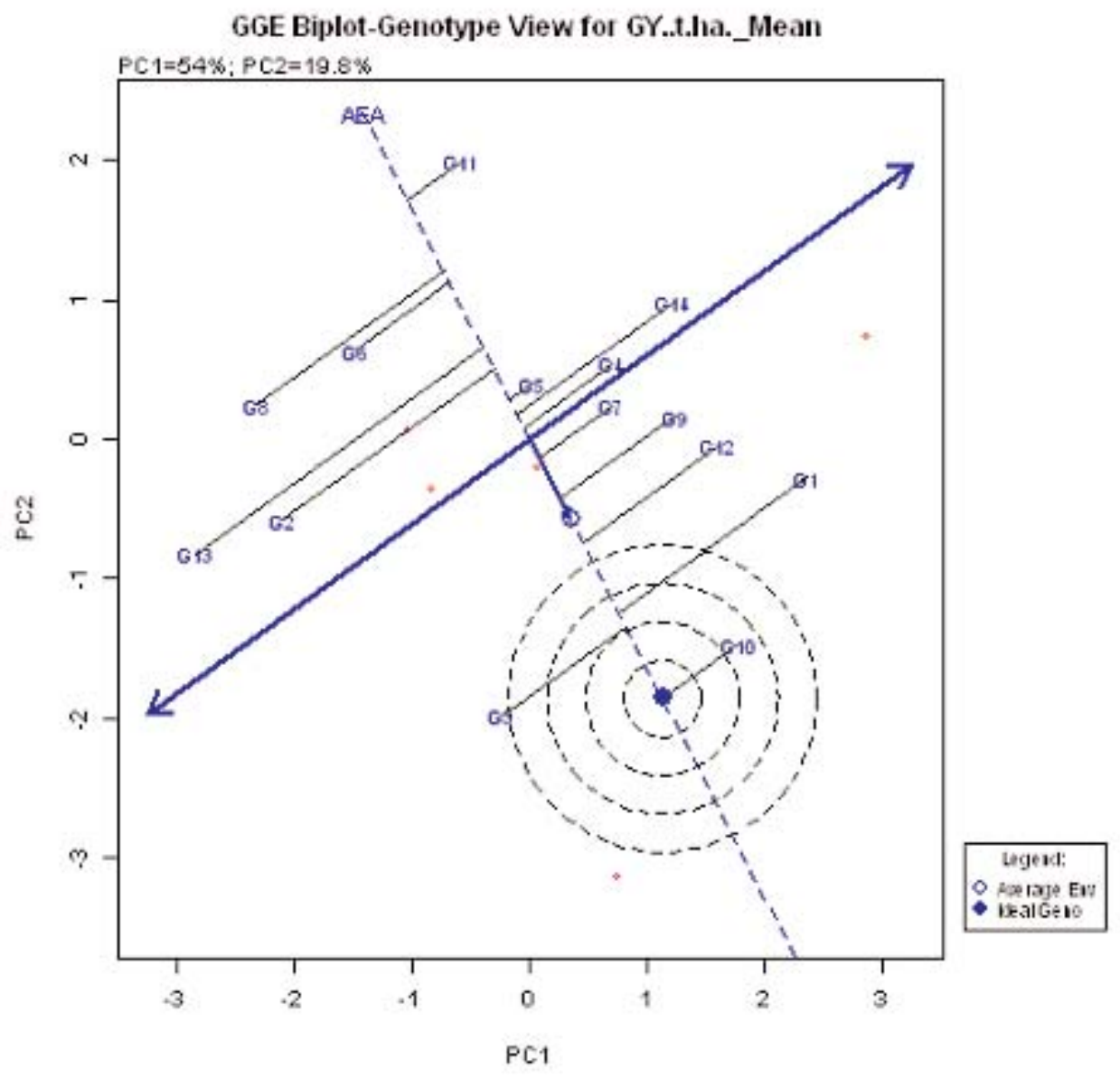

Fig. 2. Evaluation of fourteen inbred lines of maize based on both yield and stability across different environments 
stability of genotypes. A line that passes in either direction away from the biplot origin, on this axis, indicates greater $\mathrm{G}$ $\times \mathrm{E}$ interaction and reduced grain yield stability (Yan and Hunt, 2002). In the present investigation, an average tester coordinate (ATC) or average environment axis (AEA) graph (Fig. 2) was drawn based on the mean grain yield values in five locations to assess hybrid yield and stability.

According to Fig. 2, inbreds G5 and G7 had average grain yield and high stability, whereas the inbred G10 had high grain yield and high stability. The inbred G11 had low grain yield and high stability, while G13 had near average grain yield and low stability. Generally, it seems that the inbred G10 with acceptable stability and grain yield parallel to ideal genotype is the best inbred (Fig. 2).

The GGE biplot analysis permits comparing the test inbreds to a reference inbred. This method denotes the position of an "ideal" genotype that has the highest average value of all genotypes and is perfectly stable, i.e., it states no $\mathrm{G} \times \mathrm{E}$ interaction. The hypothetical ideal genotype, however, is determined built on the most stable genotype with the maximum grain yield. This genotype is determined as the genotype with the highest segment on the mean vector of higher yielding genotypes, and play minimum in the $\mathrm{G} \times \mathrm{E}$ interaction phenomenon.

In Fig. 2, the hypothetical ideal genotype is shown as a small closed circle on the axis of average genotype yield. To use the ideal genotype in the role of the measurement origin, concentric circles were drawn in the biplot to graphically ascertain the gap between the test genotypes and the ideal one (Fig. 2). A genotype that is located at the center of the circles or the genotype adjacent to the ideal (hypothetical) genotype is considered a superior genotype with high grain yield and good yield stability. Inbred G10 was the closest to the hypothetical ideal genotype and therefore identified as the best one, while inbred G11 was extremely far away from it and thus not in the ideal inbred category.

Results of the graphical study of $\mathrm{G} \times \mathrm{E}$ interaction effects confirmed that environments justified the large proportion of observed differences in the $\mathrm{G} \times \mathrm{E}$ interaction pattern. The GGE biplot approach was used effectively for grouping different environments in this investigation, and recognizing stable genotypes with good adaptation to diverse environmental conditions.
Assessment of relationship between test environments could explain the relationships among environments and tells upcoming plan and experiments. In the event of a strong positive correlation between two or more environments, the considered experiments could be conducted in one environment and the results obtained generalized to the others (Yan and Kang, 2003). In the graph drawn for this intention, the cosine of the angle between environment vectors stands for correlation strength. If it is $0^{\circ}$, the association between them is +1 . In contrast, cosine $90^{\circ}$ stands for a null correlation, while cosine $180^{\circ}$ represents a correlation of -1 .

The vectors of E3 and E4 created a very small angle and their correlation was close to +1 , which indicates that these environments had a strong positive association with each other (Fig. 3). Therefore, the results of environment Rahmatpur (E3) could be applied in the case of environment (Hathazari (E4) with more reliability. Nearly similar trend was also observed in case of Jessore (E1) and Joydebpur (E2). On the other hand, the correlation of Rahmatpur (E3) and Hathazari (E4) with Debiganj (E5) were almost null. This phenomenon implies that the reactions of the test inbreds in E5 (Debigonj) were not the same as those in Rahmatpur (E3) and Hathazari (E4). So, the results of environments were independent and could not be generalized.

Discriminating ability and representativeness of the environments is presented in Fig. 3. An ideal environment is the one that is most discriminating for genotypes (longest distance between the marker of the environment to the plot origin, is a measure of its discriminating ability) and is representative (shortest projection from the marker of location onto the ATC Y-axis is the measurement of its representativeness) of all other environments (Yan, 2001; Yan and Kang, 2003). Considering this, Rahmatpur (E3) was the most discriminating in addition to largely representative, as it is far away from the plot origin and had the shortest projection onto ATC Y-axis, respectively. According to Tonk et al. (2011), this is the best environment for genetic differentiation of experimental inbreds.

On the other hand, the environments Hathazari (E4), Joydebpur (E2) and Jessore (E1) were not far away from the origin hence were not discriminating. Besides, the environments Debiganj (E5), Jessore (E1) and Joydebpur (E2) were not representative, because they had large projection onto the ATC Y-axis (Fig. 3). 


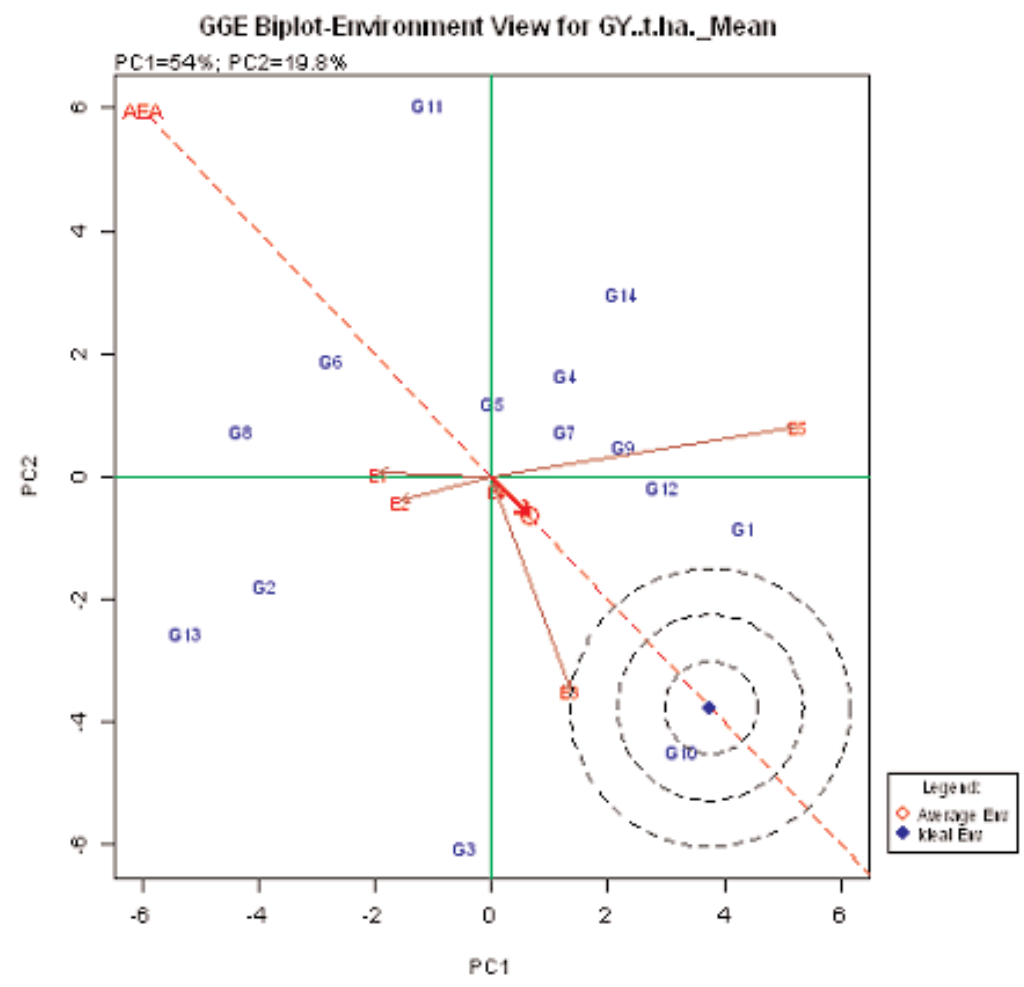

Fig. 3. A genotype + genotype $\times$ environment interaction biplot showing relationships among five environments

\section{Conclusion}

The GGE biplot analysis identified the inbreds G2 and G13 to be the most desirable inbreds for growing in Jessore (E1), G6 and G8 in E2 (Gazipur), G3 in Rahmatpur (E3) and G1, G12, G14 and G9 in Debiganj (E5) region. The inbreds G5 and G7 had average grain yield and high stability, whereas the inbred G10 had high grain yield and high stability. However, the inbred G13 was the least stable across test environments. Moreover, the GGE biplot methodology was useful tool for identification of environments in which maize inbreds will have the best possible performance. This method can carry out as a useful device for recommendation of maize inbreds for specific growing regions taking into account the specificities of inbreds and growing conditions.

\section{References}

Bavandpori F, Ahmadi J and Hossaini SM (2015), Stability analysis of bread wheat landraces and genotypes using GGE-BIPLOT, J. Biodiversity Env. Sci. 7(1): 482492.

Becker HB and Leon J (1988), Stability analysis in plant breeding, Plant Breeding. 101: 1-23.

Blanche SB and Myers GO (2006), Identifying discriminating locations for cultivar selection in Louisiana, Crop Sci. 46: 946-949.
Brandiej E and Meverty BE (1994), Genotype $\times$ environmental interaction and stability of seed yield of oil rapeseed, Crop Sci. 18: 344-353.

Choukan R (2011), Genotype, environment and genotype $\times$ environment interaction effects on the performance of maize (Zea mays L.) inbred lines, Crop Breed J. 1(2): 97-103.

Cornelius PL and Crossa J (1999), Prediction assessment of shrinkage estimators of multiplicative models for multi-environment cultivar trials. Crop Sci. 39: 9981009.

Dehghani H, Ebadi A and Yousefi A. (2006), Biplot analysis of genotype by environment interaction for barley yield in Iran, Agron. J. 98: 388-393.

Dimitrios B, Christos G, Jesus R and Eva B (2008), Separation of cotton cultivar testing sites based on representativeness and discriminating ability using GGE Biplots. Agron. J. 100: 1230-1236.

Fan XM, Kang MS, Chen H, Zhang Y, Tan J and Xu C (2007), Yield stability of maize hybrids evaluated in multi-environment trials in Yunnan, China. Agron. J. 99: $220-228$.

FAO (Food and Agriculture Organization of the United Nations), (2015), FAOSTAT, Retrieved August 26, 2015 from http://faostat3.fao.org/download/Q/QC/E. 
Gabriel KR (1971), The biplot graphic display of matrices with application to principal component analysis, Biometrika. 58: 453-467.

Gauch HG (2006), Statistical analysis of yield trials by AMMI and GGE, Crop Sci. 46: 1488-1500.

Gauch, HG and Zobel RW (1997), Identifying megaenvironments and targeting genotypes, Crop Sci. 37: 311-326.

Gerpacio VR and Pingali PL (2007), Tropical and subtropical maize in Asia: Production systems, constraints and research priorities, Mexico, D.F.: CIMMYT. 93 pp.

Hallauer AR (1990), Methods used in developing maize inbreds, Medica, 35: 1-16.

Hallauer AR and Miranda JB (1988), Quantitative genetics in maize breeding. 2nd ed. Iowa State University Press, Ames, Iowa.

Karimizadeh R, Dehghani H and Dehghanpour Z (2006), Determination of genotypic ranks and stability of corn hybrids (Zea mays L.) by non-parametric statistics, Iran J Agric Sci. 37: 381-388. (In Persian.)

Kaya Y, Akcura M and Taner S (2006), GGE-biplot analysis of multi-environment yield trials in bread wheat, Turk J Agric Forest. 30: 325-337.

Kempton RA (1984), The use of bi-plots in interpreting variety-by-environment interactions, J Agric Sci. (Camb.) 103: 123-135.

Lamkey KR and Lee M (1993), Quantitative genetics, molecular markers, and plant improvement, pp.104115. In: Imrie BC and Hacker JB (Eds), Focused plant improvement: Towards responsible and sustainable agriculture. Proc. 10 Australian Plant Breeding Conf., Gold Coast, 18-23 April 1993. Organizing Committee, Australian Convention and Travel Service, Canberra.

Letta T, D'Egidio MG and Abinasa M (2008), Analysis of multi-environment yield trials in durum wheat based on GGE-biplot electronic resource, J Food, Agric Environ. 6(2): 217-221.

Meseka SK, Menkir A and Ibrahim AES (2008), Yield potential and yield stability of maize hybrids selected for drought tolerance, J Appl Biosci. 3: 82- 90.

Mohammadi R, Amri A and Ansari Y (2009), Biplot Analysis of rain-fed barley multi-environment trials in Iran. Agron J. 101: 789-796.

Mohammadi R, Armion M, Zadhasan E, Ahmadi MM and Ahari DS (2012), Genotype $\times$ environment interaction for grain yield of rainfed durum wheat using the GGE bipot model. Seed Plant Improv J. 28-1(3): 503-518 (In persian).
Mohammadi R, Haghparast R, Amri A and Ceccarelli S (2010), Yield stability of rainfed durum wheat and GGE biplot analysis of multi-environment trials, Crop Past Sci. 61: 92-101.

Moreno-Gonzalez J, Crossa J and Cornelius PL (2004), Genotype $\times$ environment interaction in multienvironment trials using shrinkage factors for AMMI models, Euphytica. 137: 119-127.

Perkins JM and Jinks JL (1971), Environmental and genotype environment components of variability. III. Multiple line and crosses, Hered. 23: 339-356.

Sabaghnia N, Dehghani H and Sabaghpour SH (2008), Graphic analysis of genotype $\times$ environment interaction for lentil (Lens culinaris Medik) yield in Iran, Agron J. 100: 760-764.

Samonte SOPB, Wilson LT, McClung AM and Medley JC (2005), Targeting cultivars onto rice growing environments using AMMI and SREG GGE biplot analysis, Crop Sci. 45: 2414-2424.

Shiri M (2013), Grain yield stability analysis of maize (Zea mays L.) hybrids in different drought stress conditions using GGE biplot analysis, Crop Breed J. 3(2):107112.

Shiri M, Choukan R and Aliyev RT (2010), Drought tolerance evaluation of maize hybrids using biplot method, Trends Appl Sci Res. 5: 129-137.

Yan W and Hunt LA (2002), Biplot analysis of diallel data, Crop Sci. 42: 21-30.

Yan W and Kang MS (2003), GGE biplot analysis: A graphical tool for breeders, geneticists and agronomists, CRC Press, Boca Raton, FL, USA. 288 pp.

Yan W and Rajcan I (2002), Biplot analysis of test sites and trait relations of soybean in Ontario. Crop Sci. 42: 11-20.

Yan W and Tinker NA (2006), Biplot analysis of multi-environment trial data: Principles and applications, Can J Plant Sci. 86: 623-645.

Yan W, Cornelius PL, Crossa J and Hunt LA (2001), Two types of GGE biplots for analyzing multienvironment trial data, Crop Sci. 41: 656-663.

Yan W, Hunt LA, Sheng Q and Szlavnics Z (2000), Cultivar evaluation and mega-environment investigations based on the GGE biplot, Crop Sci. 40: 597-605.

Received: 20 September 2015 ; Revised: 10 Novmber 2015; Accepted: 31 January 2016. 